\title{
The Relationship of Ghrelin Level with Levels of Cluster of Differentiation 4 (CD4) in Human Immunodeficiency Virus (HIV) Patients Receiving Antiretroviral (ARV) Therapy
}

\author{
Ibrahim Tanaka ${ }^{1}$, Dharma Lindarto ${ }^{2}$, Santi Syafril ${ }^{2}$ \\ ${ }^{1,2}$ Department of Internal Medicine, Faculty of Medicine, University Sumatera Utara, H. Adam Malik General \\ Hospital Medan, Indonesia. \\ Corresponding Author: Ibrahim Tanaka
}

\begin{abstract}
Background: Ghrelin is primarily involved in the secretion of growth hormone $(\mathrm{GH})$, glucose and lipid metabolism. HIV infection is thought to affect ghrelin levels in HIV patients, especially in patients with lipodystrophy. However, this effect is still unclear because many studies have obtained different results about low or high levels of ghrelin in people with HIV. Suppression of HIV replication with ART rapidly increases CD4 cell count. However, data on the effect of antiretroviral therapy on ghrelin levels is still scant.
\end{abstract}

Aim: To examine the relationship between ghrelin levels and CD4 levels in HIV patients receiving ARV therapy.

Method: This research is an observational analysis study, with cross-sectional design, implemented start from April 2020 in Tropical Diseases \& Infection Polyclinic, H. Adam Malik Hospital. Blood samples were taken and examined at the Clinical Pathology Laboratory. Primary and secondary data collection from interviews and direct observation. Data will be analyzed with Pearson correlation test if normally distributed or Spearman's test if the data is not normally distributed using SPSS software.

Results: A total of 43 the sample consists of 38 patient who received the AFC, 3 patients received Duviral + Efafirens, 1 patient received Tenofovir + Hiviral + Aluvia dan 1 patient received Tenofovir + Hiviral + Neviral. Demographic characteristics based on th highest ages group are 21-30 years and 31-40 years, each of which is 17 people. The correlation of ghrelin level with levels of CD4 on the HIV patient taking ARV shows a significance value of 0.943 , it can be concluded that there was no significant relationship between Ghrelin levels and CD4.

Conclusion: There was no correlation between ghrelin levels with CD4 levels on HIV patient receiving ARV therapy.

Keywords: Ghrelin, HIV, CD4, Antiretrovirals

\section{INTRODUCTION}

Ghrelin is an orexigenic polypeptide (that stimulates appetite and increases food intake), consists of 28 amino acids, and secreted mainly by P/DI cells lining the gastric fundus. ${ }^{[1]}$ Ghrelin is primarily involved in growth hormone $(\mathrm{GH})$ secretion, appetite stimulation and food intake. Secondary functions include promotion of gastric acid secretion, increased intestinal motility, regulation of body weight, glucose and lipid metabolism, and suppression of inflammation. ${ }^{[2,3]}$

Falasca et al reported that HIV positive patients with hypertriglyceridemia exhibited lower mean serum ghrelin levels than patients with normal triglyceride values $(768 \pm 596 \mathrm{pg} / \mathrm{dl}$ vs $470 \pm 248, \mathrm{p}=0.01)$, these results suggest a role of ghrelin in metabolic disorders associated with HIV infection. ${ }^{[4]}$ 
CD4 $\mathrm{T}$ cells are central mediators of the immune response in humans, crucially coordinating cellular and humoral immune responses against infection. Normal adults have about $22 \times 10^{11} \mathrm{CD} 4$ cells, whereas in HIV-infected people, this number is halved when the peripheral blood CD4 cell count drops to 200 cells/microliter of blood. Reported that suppression of HIV replication with antiretroviral therapy rapidly increased peripheral blood CD4 cell counts and corrected immune deficiency. ${ }^{[5]}$

Low ghrelin levels reported by Koutkia et al in HIV lipodystrophic patients, when compared with non-lipodystrophic HIV patients. This may suggest a process directly related to HIV infection that negatively impacts ghrelin. ${ }^{[6]}$ On the other hand, Freitas et al reported significantly increased levels of ghrelin in HIV-infected patients compared with uninfected subjects. ${ }^{[7]}$ Rivera-leon et al in their study concluded that administration of ARVs (tenofovir/emtricitabine lopinavir/ritonavir) for 36 weeks in HIVinfected patients who had never received antiretroviral drugs did not show significant changes in ghrelin levels, but in a previous study they found that ghrelin levels in HIVinfected patients were significantly lower than in healthy people (177.6 \pm 72.8 $\mathrm{pg} / \mathrm{mL})^{[8]}$

Looking at the results of existing studies, there is still controversy about how ghrelin levels are in patients with HIV infection and data about how the effect of antiretroviral therapy on ghrelin levels is still scant. The purpose of this study was to determine the relationship between ghrelin levels and CD4 levels in HIV patients receiving ARV therapy.

\section{MATERIAL AND METHODS}

This research is an observational analytic study with a cross-sectional design. Research carried out start from April 2020 until the total number of samples is met, in Polyclinic Tropical Diseases and Infections of H. Adam Malik Hospital with the approval from the Research Ethics
Commission of Medical Faculty of University of Sumatera Utara. The collection and examination of blood samples was carried out by the Clinical Pathology Laboratory of $\mathrm{H}$. Adam Malik Hospital.

The number of samples are 43 patients who met the inclusion and exclusion criteria. The inclusion criteria are patients aged 18-60 years and ready to take part in research as well as have been on ARV treatment for at least 2 months. While the exclusion criteria are Human immunodeficiency virus (HIV) patients with other comorbid diseases such as diabetes, heart disease, kidney disorders, malignancies, and immunological disorders.

Subjects who met the criteria were given an explanation and if they agreed, they would be asked to give written informed consent to participate in the study. Primary and secondary data collection from interviews as well as direct observation to find out the age, gender, education level, marital status, body mass index, waist circumference, HIV stage, antiretroviral therapy received by the patient and the duration of use of the ARV. Aside from that, blood tests are carried out to obtain levels of ghrelin and CD4 by using ELISA method.

\section{Statistical Methods}

Data analysis using SPSS software aims to see the correlation of levels of Ghrelin and CD4 using the Pearson correlation test if both groups of data are normally distributed and if not normally distributed, the Spearman correlation test is used. All statistical tests with $\mathrm{p}<0.05$ were considered significant.

\section{RESULT}

In this study, the number of samples with a total of 43 patients. Male sex has the largest percentage of 31 people (72.1\%). The most age groups are $21-30$ years old and $31-40$ years old, each of which is 17 people (39.5\%). Marital status in the 
dominant subject is married as many as 25 people (58.1\%).

Table 1. Characteristics of Research Subjects

\begin{tabular}{|l|l|l|}
\hline \multicolumn{4}{|c|}{ Demographic Characteristics } & n & \% \\
\hline Gender & 31 & 72.1 \\
\hline Man & 12 & 27.9 \\
\hline Woman & & \\
\hline Age & 17 & 39.5 \\
\hline $21-30$ years old & 17 & 39.5 \\
\hline $31-40$ years old & 8 & 18.6 \\
\hline $41-50$ years old & 1 & 2.3 \\
\hline$>$ 50 years old & & \\
\hline Level of education & 1 & 2.3 \\
\hline Primary school & 3 & 7.0 \\
\hline Junior High School & 34 & 79.1 \\
\hline Senior High School & 5 & 11.6 \\
\hline Bachelor & & \\
\hline Marital Status & 18 & 41.9 \\
\hline Not married yet & 25 & 58.1 \\
\hline Married & & \\
\hline Body mass index & 7 & 16.3 \\
\hline Not enough & 29 & 67.4 \\
\hline Normal & 7 & 16.3 \\
\hline Overweight & & \\
\hline Waist size & 38 & 90.7 \\
\hline Normal & 4 & 9.3 \\
\hline Over & & \\
\hline HIV stage & 38 & 88.4 \\
\hline 3 & 5 & 11.6 \\
\hline 4 & & \\
\hline Type of ARV & 38 & 88.4 \\
\hline FDC & 3 & 7.0 \\
\hline Duviral + Efafirens & 1 & 2.3 \\
\hline Tenofovir + Hiviral + Aluvia & 1 & 2.3 \\
\hline Tenofovir + Hiviral + Neviral & $23(2-96)$ & months \\
\hline Duration of ARV use & & \\
\hline & & \\
\hline
\end{tabular}

Based on the Body Mass Index, the majority of subjects had a normal BMI category as many as 29 people (67.4\%). Most subjects had normal waist circumference as many as 39 people (90.7\%). Based on the stage of HIV, the most subjects suffered from stage $3 \mathrm{HIV}$ infection as many as 38 people (88.4\%).

Based on the type of ARV given, most of the subjects were given FDC as many as 38 people (88.4\%), followed by Duviral + Efafirens as many as 3 people (7.0\%), Tenofovir + Hiviral + Aluvia as many as 1 person (2.3\%) and 1 person (2.3\%) received Tenofovir + Hiviral + Neviral. The median duration of ARV use in this study was 23 months, with the lowest value being 2 months and the highest value being 96 months.

Table 2. Subject Laboratory Characteristics

\begin{tabular}{|l|l|}
\hline Demographic Characteristics & Mean \pm SD \\
\hline CD4 levels after therapy & $375.9 \pm 373.4$ \\
\hline Ghrelin levels & $2713(19.6-5.128) *$ \\
\hline \multicolumn{2}{|c|}{ * Distribution is not normal }
\end{tabular}

The subjects' mean CD4 levels were $375.9 \pm 373.4$. The median ghrelin level of the subjects was 2713 (19.6-5.128).

Table 3. Nutritional status, ghrelin levels and CD4 levels in HIV patients by stage

\begin{tabular}{|c|c|c|c|}
\hline \multirow[t]{2}{*}{ Characteristics } & \multicolumn{3}{|l|}{ HIV Stage } \\
\hline & 3 & 4 & p value* \\
\hline Ghrelin & $2669.66 \pm 1112.68$ & $2545.80 \pm 458.05$ & 0.8 \\
\hline CD4 & $388.73 \pm 388.41$ & $278.60 \pm 234.87$ & 0.54 \\
\hline Waist size & $80.18 \pm 7.26$ & $75.20 \pm 9.50$ & 0.17 \\
\hline BMI & $21.63 \pm 3.56$ & $20.12 \pm 3.36$ & 0.37 \\
\hline
\end{tabular}

There were no significant differences in ghrelin levels, CD4 levels, waist circumference, and BMI based on HIV stage $(\mathrm{p}>0.05)$.

\begin{tabular}{l} 
Table 4. Relationship of nutritional status with ghrelin levels and CD4 levels \\
\begin{tabular}{|l|l|l|l|l|}
\hline Nutritional Status & Ghrelin & p value & CD4 & p value \\
\hline BMI & & & & \\
\hline Not enough & $2804.86 \pm 902.00$ & $0.83^{*}$ & $397.71 \pm 338.13$ & $0.97 *$ \\
\hline Normal & $2667.28 \pm 1159.69$ & & $377.69 \pm 415.91$ & \\
\hline Overweight & $2455.86 \pm 789.24$ & & $346.86 \pm 230.00$ & \\
\hline Waist size & & & & \\
\hline Normal & $2655.59 \pm 1085.79$ & $0.99 *$ & $381.23 \pm 382.88$ & $0.78^{* *}$ \\
\hline Over & $2652.00 \pm 799.01$ & & $324.25 \pm 302.12$ & \\
\hline
\end{tabular} \\
\hline
\end{tabular}

There was no significant difference in mean ghrelin levels and CD4 levels based on nutritional status.
Correlation of Ghrelin Levels with CD4 Levels On HIV Patients who Received Antiretroviral (ARV) Therapy

Based on data of normality test it was found that data is normally distributed. Then the Pearson correlation test can be 
continued to determine the correlation of Ghrelin and CD4 levels.

Table 5. Rate correlation Ghrelin and CD4 on the patient HIV who men could Antiretroviral Therapy (ARV)

\begin{tabular}{|l|l|l|}
\hline Spearman's Correlation & CD4 Levels \\
\hline \multirow{2}{*}{ Ghrelin } & Correlation coefficient & -.011 \\
\cline { 2 - 3 } & P value & .943 \\
\hline
\end{tabular}

*Pearson correlation test

Table 2 shows a significance value of 0.943 then it can be concluded that there is no correlation between the levels of Ghrelin and CD4 because significance value (p) $>0.05$.

\section{DISCUSSION}

In this study the number of samples are 43 patients consists of 38 patients received AFC, 3 patients received Duviral + Efafirens, 1 patient received Tenofovir + Hiviral + Aluvia dan 1 patient received Tenofovir + Hiviral + Neviral. Demographic characteristics by the highest ages group are 21-30 years and 31-40 years, each of which is 17 people. Male HIV sufferers had the largest percentage of 31 people $(72.1 \%)$ according to the data from the Directorate General of P2P sourced from the 2019 HIV, AIDS and STI Information System (SIHA), in the fourth quarter report, it was stated that cases of HIV and AIDS in men is higher than women. ${ }^{[9]}$

Subjects with a high school education with the highest proportion based on education level were 34 people (79.1\%). The same thing was found in a study by Tuntufye regarding the level of education associated with knowledge about HIV/AIDS in Kenya with the result that knowledge of HIV/AIDS in college students was higher than that of high school students. ${ }^{[10]}$

Rahman et al, in Bangladesh investigated knowledge and awareness of adolescents about HIV/AIDS. It was concluded that the number of years of schooling was correlated with their knowledge of HIV/AIDS. ${ }^{[11]}$ Likewise Jukes et al, states that educating girls in schools serves as a shield against the risk of contracting HIV/AIDS. It was further stated that there is a relationship between education level and the chance of contracting HIV/AIDS, so that the higher the level of education, the less likely it is to be infected with HIV/AIDS. Girls who remain in primary and secondary schools contribute to a lower likelihood of becoming HIV/AIDS positive. ${ }^{[12]}$

Marital status in the dominant subject is married as many as 25 people (58.1\%). In contrast to the results of this study, Boikhutso explained that the prevalence of HIV was $10.6 \%$ for the entire study population and the highest among widows $(11.4 \%)$, followed by married but separated (11\%), never married (10.9\%), divorced (10.5\%), monogamous (7.7\%) and polygamous (7.1\%). A study conducted in Uganda also found that people who were monogamously married were less likely to be infected with HIV than those who were never married. ${ }^{[13]}$ The explanation that can be put forward regarding this difference in results is the decrease in sexual activity in unmarried couples due to eastern customs from Asian culture and the fact that divorce in cultures in Asia, especially Indonesia is still taboo because it is related to the good name of the family, resulting in infidelity in polygamous marriages which can lead to infidelity in polygamous marriages. lead to a high risk of HIV infection among other members of a polygamous relationship. Husbands are mostly the source of the virus in polygamous marriages, as they migrate to urban areas in search of job opportunities, and this encourages more sexual partners. ${ }^{[14]}$

Based on Body Mass Index (BMI), the majority of subjects had a normal BMI category as many as 29 people (67.4\%). Most subjects had normal waist circumference as many as 39 people $(90.7 \%)$. In contrast to the results of this study, research by Lori et al found that the HIV-infected group was $13.4 \%$ overweight compared to the HIV-uninfected group. Twenty-two percent of the HIV-infected group were obese compared to the HIVuninfected group. Although the data in this study support a normal BMI in HIVinfected adolescents, compared with other studies it may also be due to a poor diet 
different. These lifestyle factors may contribute to the high rates of overweight and obesity in people with HIV. ${ }^{[15]}$

Based on the stage of HIV, the most subjects suffered from stage 3 HIV infection as many as 38 people (88.4\%). Reselinda \& Vivi's research also found that the majority of the subjects in their study were advanced stages of HIV, namely HIV stages 3 and 4 . This was probably due to at least stage 1 and 2 HIV sufferers who underwent examinations at the hospital because there were no or minimal symptoms. The development of opportunistic infections such as tuberculosis (TB) among HIVinfected persons is associated with immunosuppression. The risk increases as the degree of immunosuppression increases, with people with stage $4 \mathrm{HIV}$ who are immunosuppressed have a higher risk of developing TB infection than those who are not immunosuppressed. ${ }^{[16]}$

The mean CD4 cell count after therapy was $375.9 \pm 373.4$, and the median ghrelin level was 2713 (19.6-5.128) ng/ml. Research by Rivera-Leon et al, regarding Ghrelin levels in HIV patients who underwent ARV therapy for 36 weeks, reported that the median CD4 level of patients after 36 weeks of ARV therapy was 544 cells $/ \mu \mathrm{L}$ and the median Ghrelin level was $64.15(49.3-82.8) \mathrm{ng} / \mathrm{ml}$. There were no significant differences in ghrelin levels, CD4 levels, waist circumference, and BMI based on HIV stage. ${ }^{[8]}$ Ghrelin has a pulsatile secretion with maximal blood concentrations before meals and decreases after ingestion, and also exhibits high concentrations in negative energy balance situations and low concentrations in obese individuals. [17] There was no significant difference in mean ghrelin levels and CD4 levels based on nutritional status. Research by Mahlangu et al, it was found that the prevalence of obesity and overweight was higher in HIV patients taking antiretroviral therapy for a period of 6-48 months. ${ }^{[18]}$ Research by Feleke et al, reported that there was no relationship between nutritional status and CD4 cell count in HIV patients receiving $A R T .{ }^{[19]}$

Based on the Spearman correlation test in this study, there was no significant relationship between Ghrelin levels and CD4 cells. The state of hypertriglyceridemia can affect ghrelin levels in the body. One study by Falasca et al, compared ghrelin levels among HIV-infected patients with and without hypertriglyceridemia, found that hypertriglyceridemic patients had higher ghrelin levels and that ghrelin and triglyceride levels were correlated among these patients, suggesting a role for ghrelin in HIV-associated metabolic disorders. ${ }^{[4]}$ The gastrointestinal system is the main site of HIV replication. HIV enteropathy is characterized by chronic inflammation of the intestinal mucosa due to extensive depletion of CD4+ T cells accompanied by decreased mucosal repair and regeneration. It is likely that intestinal ghrelin-producing cells are affected in number or function and the decrease in numbers observed in HIV patients is a consequence of this process. The use of ART efficiently suppresses viral replication but is not as efficient in restoring the patient's immune function. Thus, partial restoration of immune and gut barrier function after ART may be reflected as an increase in ghrelin levels although they remain lower than in healthy subjects. Through the explanation of the mechanism above, it can be seen that there is a relationship between ghrelin and CD4+. ${ }^{[20]}$

The advantage of this study that it is the first study to assess the relationship between Ghrelin levels and CD4 cells in HIV patients receiving ARV therapy. However, this study has limitations, namely a cross-sectional research method, so it cannot see changes in the variables studied before and after receiving ARV therapy.

\section{CONCLUSION}

There was no association between Ghrelin levels and CD4 cells in HIV patients receiving ARV therapy. There were no significant differences in ghrelin levels, CD4 levels, waist circumference, and BMI 
based on HIV stage. Also, there was no significant difference in mean ghrelin levels and CD4 levels based on nutritional status.

\section{Acknowledgement: None}

\section{Conflict of Interest: None}

\section{Source of Funding: None}

\section{Ethical Approval: Approved}

\section{REFERENCES}

1. Kojima M, Kangawa K. Ghrelin: a novel growth-hormone releasing peptide. Nihon Rinsho. 2001;59:1400-7

2. Higgins SC, Gueorguiev M, Korbonits M. Ghrelin, The peripheral hunger hormone. Ann Med. 2007;39(2):116-136.

3. López M, Lage R, Saha AK, Pérez-Tilve $\mathrm{D}$, Vazquez MJ, Varela L, et al. Hypothalamic fatty acid metabolism mediates the orexigenic action of ghrelin. Cell Metab. 2008;7(5):389-399.

4. Falasca K, Manigrasso MR, Racciatti D, Zingariello P, Dalessandro M, Ucciferri C, et al. Associations between hypertriglyceridemia and serum ghrelin, adiponectin, and IL-18 levels in HIVinfected patients. Ann Clin Lab Sci. 2006;36(1):59-66.

5. Naive HM. Pathogenesis of HIV Infection. Infect Dis Rep.2013;5(Suppl 1):e6. doi:10.4081/idr.2013.s1.e6.

6. Koutkia P, Meininger G, Canavan B, Breu J, Grinspoon S. Metabolic regulation of growth hormone by free fatty acids, somatostatin, and ghrelin in HIVlipodystrophy. Am J Physiol Endocrinol Metab. 2004;286(2):E296-303.

7. Freitas $P$, Carvalho $D$, Santos AC, Madureira AJ, Martinez E, Pereira J, et al. Adipokines, hormones related to body composition, and insulin resistance in HIV fat redistribution syndrome. BMC Infect Dis. 2014;14:347.26.

8. Rivera-Leon EA, Llamas-Covarrubias IM, Soria-Rodriguez RA, Sanchez-Enriquez S, González-Hernández LA, AndradeVillanueva JF, et al. Serum ghrelin and obestatin levels in HIV-infected patients: Effect of 36 weeks of antiretroviral treatment. Endocrinology, diabetes and nutrition. 2019;66(1):4-10.

9. Indonesian Ministry of Health. Situation Report on the Development of HIV AIDS and PIMS in Indonesia, Quarter IV of 2019. Jakarta: Indonesian Ministry of Health, 2020.

10. Mwamwenda TS. University Students' Knowledge of HIV/AIDS at an Adventist University in Tanzania. Med Jour of Soc Sci. 2014;5(27), 816.

11. Rahman MH, Kabir M, Shahidullah M. Adolescents' knowledge and awareness about HIV/AIDS and the factors affecting them in Bangladesh. J. Ayub Med. Col. Abbottabad. 2006;21(3)1-6.

12. Jukes M, Simmons S, Bundy D. Education and vulnerability: The role of schools in protecting young women and girls from HIV in southern Africa. AIDS. 2009;22(4):541-556.

13. Nalugoda F, Guwatudde D, Bwaninka JB, Makumbi FE, Lutalo T, Kagaayi J, et al. Marriage and the risk of incident HIV infection in Rakai, Uganda. JAIDS Journal of Acquired Immune Deficiency Syndromes. 2014;65(1):91-98.

14. Mswela M. Cultural practices and HIV in South Africa: A legal perspective. Potchefstroom Electronic Law Journal. 2009;12(4):171.

15. Sharma TS, Kinnamon DD, Duggan C, et al. Changes in macronutrient intake among HIV-infected children between 1995 and 2004. Am J Clin Nutr.2008;88(2):384-391.

16. Roselinda, Setiawaty V. The stages of HIV infection and the risk of opportunistic tuberculosis infection. Health Science Journal of Indonesia. 2015;6(2):121-125.

17. Serra-Prat, M., Palomera, E., Roca, M., Puig-Domingo, M., \& Mataró Aging Study Group. Long-term effect of ghrelin on nutritional status and functional capacity in the elderly: a population-based cohort study. Clinical Endocrinology. 2010;73(1):41-47.

18. Mahlangu, K., Modjadji, P., \& Madiba, S. The nutritional status of adult antiretroviral therapy recipients with a recent HIV diagnosis; a cross-sectional study in primary health facilities in 
Ibrahim Tanaka et.al. The relationship of ghrelin level with levels of cluster of differentiation 4 (CD4) in human immunodeficiency virus (HIV) patients receiving antiretroviral (ARV) therapy.

Gauteng, South Africa. In hormone secretagogue. J Immunol. 2001;

Healthcare.2020;8(3):290.

166(6):4195-4201.

19. Feleke, DG, Yemanebrhane, N., \& Gebretsadik, D. Nutritional Status and CD4 Cell Counts in HIV/AIDS Patients under Highly Active Antiretroviral Therapy in Addis Ababa, Ethiopia. J AIDS Clin Res. 2017;8:2-4.

20. Koo GC, Huang C, Camacho R, Trainor C, Blake JT, Sirotina-Meisher A, et al. Immune enhancing effect of a growth

How to cite this article: Ibrahim Tanaka, Dharma Lindarto, Santi Syafril. The relationship of ghrelin level with levels of cluster of differentiation 4 (CD4) in human immunodeficiency virus (HIV) patients receiving antiretroviral (ARV) therapy. International Journal of Research and Review. 2021; 8(12): 650-656. DOI: https:// doi.org/10.52403/ijrr.20211280 